\title{
Assimetrias na Transmissão dos Preços dos Combustíveis: 0 Caso do Óleo Diesel no Brasil*
}

\author{
Mauricio Canêdo-Pinheiro ${ }^{\dagger}$
}

Conteúdo: 1. Introdução; 2. Como Medir a Assimetria na Transmissão dos Preços?;

3. Descrição dos Dados; 4. Resultados; 5. Considerações Finais; A. Apêndice: Testes de Quebra Estrutural no Vetor de Cointegração.

Palavras-chave: Assimetria, Modelo de Correção de Erros, Cointegração, Preços do óleo Diesel.

Códigos JEL: C22, D40, Q40.

Existe farta evidência internacional de assimetria no ajuste dos preços, em particular com relação aos combustíveis. A literatura a este respeito com dados brasileiros é escassa e, nesse sentido, o objetivo deste artigo é suprir esta lacuna e investigar a assimetria na transmissão do preço do óleo diesel no atacado (refinarias e distribuidores) para os consumidores finais. Os resultados apontam que há assimetria e que ela se manifesta no curto e no longo prazo. Enquanto aumentos nos preços no atacado são repassados quase que totalmente no mesmo mês do choque, as reduções são repassadas de modo bem mais lento. Os resultados são robustos à presença de quebras estruturais e choques de $1 \%$ no preço no atacado implicam transferência de pelo menos $\mathrm{R} \$ 2,1$ bilhões por anos dos consumidores para os varejistas.

Despite of international evidence of asymmetric price adjustments in many markets, particularly in gasoline markets, the literature on this issue with Brazilian data is very scarce. Thus, the aim of this paper is to fill this gap and investigate the asymmetry in price transmission of wholesale diesel (refineries and distributors) to final consumers. In fact, price adjustments are asymmetric both in the short and long run. While retailer prices tend to respond to wholesale price increases in the same month, complete response to wholesale price reductions may take ten months. The results are robust

\footnotetext{
*O autor agradece a Salomão Quadros e André Braz pelos esclarecimentos sobre a metodologia de cálculo dos índices de preços usados no artigo. Agradecimentos também aos comentários de um parecerista anônimo e de diversos participantes do $V$ Encontro CAEN - EPGE de Políticas Públicas e Crescimento Econômico e do XXXIX Encontro Nacional de Economia (ANPEC). Os erros remanescentes são de inteira responsabilidade do autor. As opiniões expressas não refletem a posição do IBRE ou da FGV.

† Pesquisador do IBRE/FGV - Economia Aplicada. Endereço para contato: Rua Barão de Itambi 60, sala 801, Rio de Janeiro - RJ. CEP: 22231-000. E-mail: mauricio.pinheiro@fgv.br
} 
to the presence of structural breaks and shocks of $1 \%$ in the wholesale price mean transfer of at least $R \$ 2.1$ billion a year from consumers to retailers.

\section{INTRODUÇÃO}

Já faz parte do imaginário popular o comportamento assimétrico dos agentes econômicos no repasse de choques nos preços dos insumos para o consumidor final. No entanto, além das evidências anedóticas a esse respeito, também existe uma ampla literatura que descreve e analisa o comportamento assimétrico dos preços em resposta a alterações nos custos (para referências ver Meyer e Von Cramon Taubadel, 2004, Frey e Manera, 2007).

Interesse particular tem sido devotado ao comportamento dos preços dos combustíveis (Boreinstein et alii, 1997, Bachmeier e Griffin, 2003, por exemplo). A esse respeito, as evidências de assimetria são ambíguas, dependendo do tipo de assimetria investigada, da periodicidade dos dados e da técnica econométrica empregada (Frey e Manera, 2007).

O estudo da assimetria na transmissão dos preços tem implicações relevantes em termos de política pública. Em primeiro lugar, com relação à incidência e repasse de impostos (Alm et alii, 2008). No caso específico do Brasil, um melhor entendimento do mecanismo de transmissão dos preços dos combustíveis (possivelmente assimétrico) pode ajudar na calibragem da política de tributação destes produtos, que estão sujeitos à incidência da Contribuição de Intervenção no Domínio Econômico (CIDE). Como é usual que o governo ajuste o valor da CIDE para suavizar variações nos preços na refinaria, seria importante entender se existe assimetria com relação a aumentos e reduções dos preços no atacado.

Em segundo lugar, no que diz respeito à condução de política monetária. Se choques positivos e negativos são transmitidos de forma diferente para os consumidores finais, a resposta da autoridade monetária deveria ser diferente em cada caso. E finalmente, no que tange à competição. Como a assimetria pode estar associada ao exercício de poder de mercado coordenado, a identificação deste fenômeno pode sinalizar a necessidade de reforço no combate aos cartéis. Esta implicação ganha grande apelo quando se considera os diversos de episódios de condenação de postos de combustíveis por formação de cartel no Brasil (SDE, 2009).

No entanto, a despeito da importância do tema, a literatura com dados brasileiros é bastante escassa. Exceção pode ser feita com relação à Uchôa (2007), que investigou a presença de assimetria na transmissão dos preços internacionais do petróleo para os preços da gasolina no varejo. 0 objetivo deste artigo é justamente suprir esta lacuna, investigando no Brasil a existência de assimetria na transmissão dos preços do óleo diesel no atacado para os preços do mesmo combustível no varejo. Diferentemente de outros estudos, que tendem a se concentrar em uma determinada modalidade do fenômeno (Frey e Manera, 2007), serão testados diversos tipos de assimetria, tanto de curto quanto de longo prazo. Além disso, inova-se também ao investigar o impacto da presença de quebras estruturais nas relações de longo prazo nos testes de assimetria, tal como sugerido em Von Cramon Taubadel e Meyer (2001).

Além desta Introdução este artigo conta com quatro seções adicionais. A Seção 2 descreve o modelo de correção de erros que serve de base para a explicar o mecanismo de transmissão dos preços do diesel, bem como define precisamente os conceitos de assimetria a serem empregados ao longo do artigo. A Seção 3 descreve brevemente as séries de preços utilizadas, calculadas pela Fundação Getulio Vargas (FGV), e a Seção 4 apresenta e interpreta os resultados encontrados, bem como deriva algumas prescrições em termos de política pública. Segue-se uma seção com breves Considerações Finais.

\section{COMO MEDIR A ASSIMETRIA NA TRANSMISSÃO DOS PREÇOS?}

Não existe uma definição única de assimetria quando o tema é o repasse de choques nos preços dos insumos para os demais elos da cadeia produtiva. O interesse deste artigo é o mecanismo de transmissão dos preços do óleo diesel no atacado (distribuidores) para os preços no varejo (postos de 
combustíveis) no Brasil. Sendo assim, como ambas as variáveis de interesse são $I(1)$ e cointegradas (ver Seção 3), uma maneira conveniente de modelar a relação entre ambas é por meio de um mecanismo de correção de erros (Meyer e Von Cramon Taubadel, 2004, Frey e Manera, 2007):

$$
\triangle p_{t}=\alpha+\sum_{j=0}^{J^{+}} \beta_{j}^{+} \triangle P_{t-j}^{+}+\sum_{j=0}^{J^{-}} \beta_{j}^{-} \triangle P_{t-j}^{-}+\sum_{k=1}^{K^{+}} \gamma_{j}^{+} \triangle p_{t-j}^{+}+\sum_{k=1}^{K^{-}} \gamma_{j}^{-} \triangle p_{t-j}^{-}+\theta^{+} \mu_{t-1}^{+}+\theta^{-} \mu_{t-1}^{-}+\varepsilon_{t}
$$

em que o subscrito $t$ representa respectivamente tempo, $p_{t}$ denota o logaritmo do preço da gasolina no varejo (postos de combustíveis), $P_{t}$ o logaritmo do preço cobrado no atacado (distribuidores), $\triangle$ indica variação, $\triangle p_{t}^{+}=\max \left\{\triangle p_{t}, 0\right\}, \triangle p_{t}^{-}=\min \left\{\triangle p_{t}, 0\right\}, \triangle P_{t}^{+}=\max \left\{\triangle P_{t}, 0\right\}, \triangle P_{t}^{-}=$ $\min \left\{\triangle P_{t}, 0\right\}, \mu_{t}=p_{t}-\delta-\lambda P_{t}$ é o desvio da relação de longo prazo entre as variáveis de interesse, $\mu_{t}^{+}=\max \left\{\mu_{t}, 0\right\}, \mu_{t}^{-}=\min \{\mu, 0\}$ e $\varepsilon_{t}$ é o erro aleatório.

Em (1), os quatro primeiro somatórios se referem à dinâmica de curto prazo dos preços. Por sua vez, $\theta^{+} \mu_{t-1}^{+}+\theta^{-} \mu_{t-1}^{-}$se refere ao termo de correção de erros, ou seja, à relação de equilíbrio de longo prazo. Se as variáveis de interesse são $I(1), \delta$ e $\lambda$ podem ser estimados por mínimos quadrados ordinários e usados como parâmetros conhecidos na estimação de (1) (Engle e Granger, 1987). Em outras palavras, na estimação de (1) pode-se substituir $\mu_{t}$ desconhecido por sua contrapartida estimada e conhecida $\hat{\mu}_{t}=p_{t}-\hat{\delta}-\hat{\lambda} P_{t}$, em que o acento circunflexo indica parâmetros estimados.

É possível definir pelo menos cinco tipos de assimetria (Frey e Manera, 2007):

(i) assimetria do impacto contemporâneo $(A I C)$, se $\beta_{0}^{+} \neq \beta_{0}^{-}$;

(ii) assimetria devida ao efeito das defasagens $(A E D)$, se $\beta_{j}^{+} \neq \beta_{j}^{-}$para algum $j \in\left[0, \max \left(J^{+}, J^{-}\right)\right]$. Note-se que $J^{+} \neq J^{-}$implica $A E D$, mas não o contrário;

(iii) assimetria do impacto acumulado $(A I A)$ até a defasagem $J$, se $\sum_{j=J}^{J^{+}} \neq \sum_{j=J}^{J^{-}}$, em que $J \in$ $\left[0, \min \left(J^{+}, J^{-}\right)\right]$;

(iv) assimetria no tempo de reação $(A T R)$, se o tempo necessário para ajuste de volta ao equilíbrio é diferente para choques positivos e negativos em $P_{t}$. Ressalte-se que não se trata somente de um teste para verificar se $J^{+} \neq J^{-}$, pois envolve o cálculo das funções de ajuste cumulativo, que dependem potencialmente de todas as variáveis do modelo;

(v) assimetria na trajetória de ajuste para o equilíbrio $(A T A E)$, se $\theta^{+} \neq \theta^{-}$, ou seja, se a velocidade de convergência depende de o preço no varejo estar acima $\left(\mu_{t-1} \geq 0\right)$ ou abaixo $\left(\mu_{t-1}<0\right)$ do equilíbrio de longo prazo.

Note-se que $A I C$ e $A E D$ são assimetrias de curto prazo, pois comparam os impactos dos choques de $P_{t}$ em $p_{t}$ para um determinado momento, enquanto as demais assimetrias se referem ao longo prazo.

Outra questão importante sobre a assimetria na transmissão de choques é o ponto da cadeia produtiva objeto de análise. No caso do óleo diesel no Brasil, os quatro elos mais importantes da cadeia produtiva são:

(i) os produtores de petróleo;

(ii) as refinarias que produzirem óleo diesel a partir do petróleo;

(iii) distribuidores, que compram o óleo diesel das refinarias e misturam com biodiesel;

(iv) revendedores (postos de combustível), que vendem o diesel ao consumidor final. ${ }^{1}$

\footnotetext{
${ }^{1} \mathrm{~A}$ mistura do biodiesel também pode ser feita pela refinaria.
} 
Também existe a figura do transportador-revendedor-retalhista $(T R R)$, que compra óleo diesel dos distribuidores e revende para grandes consumidores.

A Figura 1 apresenta de forma simplificada os elos dessa cadeia produtiva. A partir do petróleo bruto, as refinarias produzem óleo diesel e outros derivados. Na refinaria (ou no importador), o preço do diesel (sem a mistura do biodiesel e já com a margem de lucro, denominado preço de realização) é acrescido da CIDE e dos impostos indiretos (PIS, COFINS e ICMS). ${ }^{2}$ Então a distribuidora faz a mistura do diesel com o biodiesel (B100), cujo preço também embute impostos indiretos. O preço de faturamento do distribuidor $(P)$ embute também o frete do óleo diesel e do biodiesel até a base de distribuição, a margem da distribuidora e o frete até o posto de combustível. O preço na bomba $(p)$ é calculado pela adição da margem do revendedor ao preço de faturamento do distribuidor. Em Uchôa (2007) o interesse é o mecanismo de transmissão do preço internacional do petróleo para o preço cobrado dos consumidores finais pelos revendedores. O objeto deste artigo é a transmissão (possivelmente assimétrica) de choques nos preços do óleo diesel no atacado (distribuidores) para os preços cobrados dos consumidores finais pelos postos de combustível.

Figura 1: Cadeia Produtiva do Óleo Diesel no Brasil

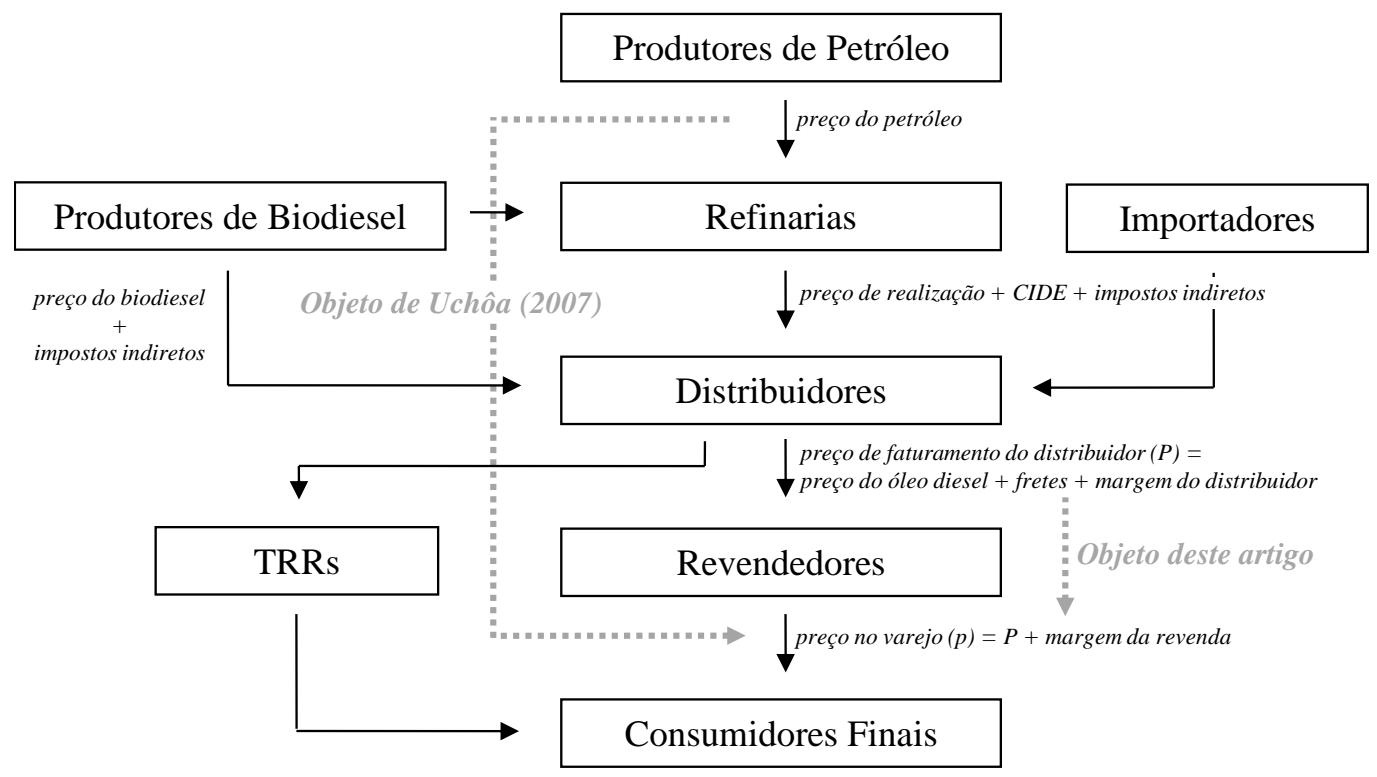

\section{DESCRIÇÃO DOS DADOS}

Para estimar o modelo descrito em (1) serão utilizados dois índices de preços calculados pela FGV. Para o preço do óleo diesel no atacado $\left(P_{t}\right)$ adotou-se o IPA - Óleo Diesel (código 23204) e para o mesmo preço no varejo $\left(p_{t}\right)$ foi usado o IPC - Óleo Diesel (código 620507). O período analisado começa em

\footnotetext{
${ }^{2}$ Todos os impostos indiretos são recolhidos nesse elo da cadeia (mecanismo de substituição tributária).
} 
janeiro de 1999, data em que a série dos preços do óleo diesel ao consumidor começou a ser disponibilizada pela $F G V$, e termina em março de 2010 , mês imediatamente anterior às mudanças metodológicas no IPA - Óleo Diesel. Tais mudanças foram realizadas na esteira da transformação do IPA da FGV em um índice de preços ao produtor. Basicamente, os preços passaram a ser pesquisados nas refinarias (e não nos distribuidores, como antes), passaram a se referir ao óleo diesel antes da mistura do biodiesel e deixaram de incluir tributos.

A Figura 2 ilustra a evolução das duas séries (em logaritmo). Nota-se clara tendência de aumento de ambos os preços até o início de 2003, ponto a partir do qual se observa certa estabilidade. Percebe-se também que os preços no varejo e no atacado evoluem de forma similar. Aparentemente quase todo o ajuste nos preços no atacado é repassado aos preços no varejo. Entretanto, percebe-se que ao longo do tempo a margem do varejo se reduziu, na medida em que o preço no atacado aumentou mais do que para o consumidor final.

Figura 2: Logaritmo do Nível dos Preços do Diesel no Atacado $\left(P_{t}\right)$ e no Varejo $\left(p_{t}\right)$

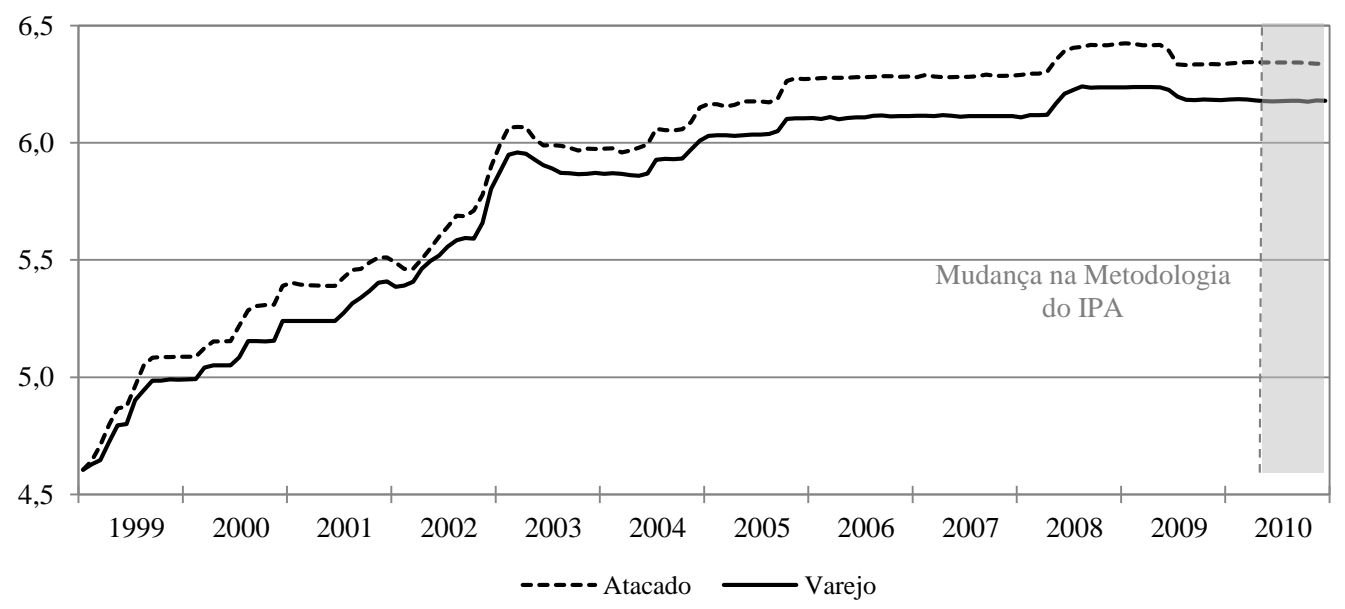

Por sua vez, a Figura 3 apresenta a evolução das mesmas séries em primeira diferença. Obviamente, as maiores variações são observadas no período inicial, até os primeiros meses de 2003. Chama atenção o fato de que variações positivas são mais comuns do que variações negativas (ver também Figura 4). Ademais, confirma-se a percepção de que os choques nos preços no atacado são transferidos quase que integralmente aos preços no varejo.

Da Tabela 1 nota-se que os resultados dos testes mais usuais (Augmented Dickey-Fuller e PhillipsPerron) indicam que $P_{t} \sim I(1)$ e $p_{t} \sim I(1)$. Entretanto, a Figura 2 parece indicar a presença de quebras estruturais nas séries de preços do óleo diesel em nível, o que tenderia a viesar os testes convencionais. Por um lado, a hipótese nula de presença de raiz unitária seria aceita em circunstâncias em que as séries seriam, na verdade, estacionárias com quebras estruturais (Perron, 1989). Por outro lado, se na verdade as séries são $I(1)$ com quebra estrutural, ocorreria justamente o contrário: rejeições espúrias da hipótese nula (Leybourne et alii, 1998). Em resumo, existe a possibilidade das séries serem, de fato, estacionárias com quebras estruturais, o que invalidaria o uso do modelo de correção de erros.

Nesse sentido, alguns autores sugerem a confirmação dos resultados com o uso de testes cuja hipótese nula seja de ausência de raiz unitária, e não de presença, como no Augmented Dickey-Fuller e no Phillips-Perron [ver Carrion-I-Silvestre et alii (2001) para referências]. Sendo assim, optou-se por aplicar 
Figura 3: Variação do Logaritmo dos Preços do Diesel no Atacado $\left(\triangle P_{t}\right)$ e no Varejo $\left(\triangle p_{t}\right)$

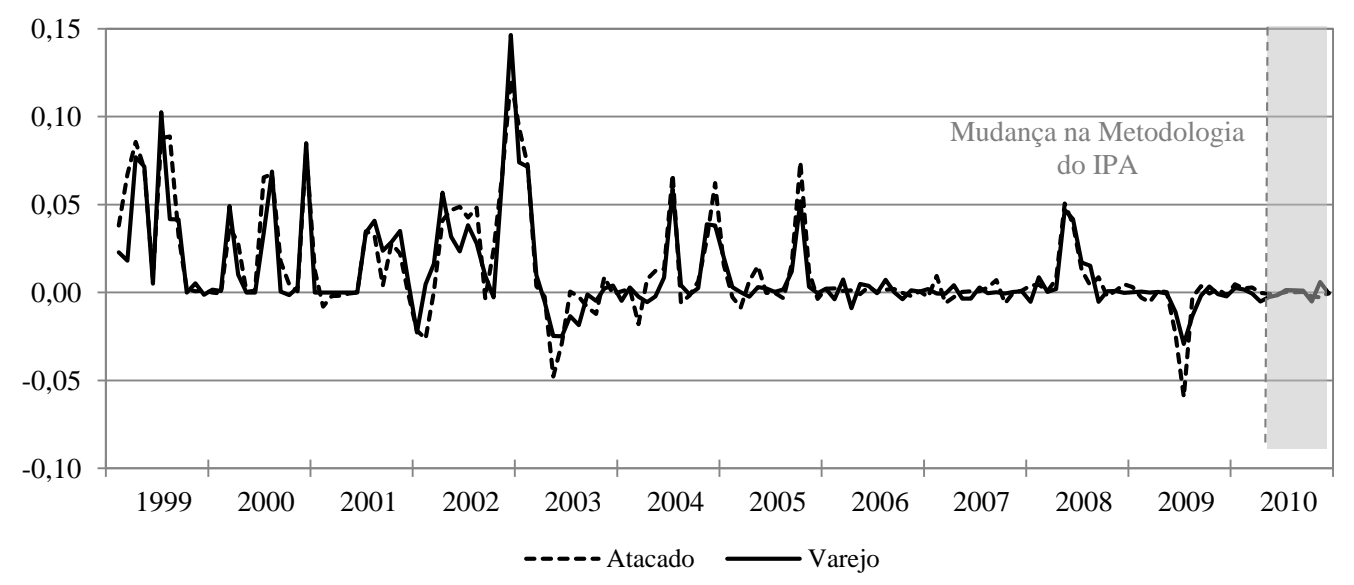

também o teste KPSS às séries de preço em nível, que novamente confirmou a presença de raiz unitária (ver Tabela 1). ${ }^{3}$

Entretanto, há evidências de que o uso concomitante de testes de raiz unitária com hipóteses nulas diferentes não resolve o problema gerado pela presença de quebras estruturais (Keblowski e Welfe, 2004). Em outras palavras, mostra-se necessário usar testes que levam em consideração a possibilidade de quebras estruturais nas séries de interesse. Desse modo, optou-se pelo teste proposto em Lee e Strazicich (2003), doravante $L S$. Trata-se de um teste que prevê a possibilidade de duas quebras estruturais endogenamente calculadas e cuja hipótese nula é de que a série de interesse possui raiz unitária. Mais uma vez, os resultados desse teste confirmam que, de fato, as séries de preços do óleo diesel no atacado e no varejo possuem raiz unitária (ver Tabela 1 ).

Além disso, os testes convencionais de cointegração parecem apontar que os preços do óleo diesel no atacado e no varejo não são cointegrados. Apenas o teste de Engle-Granger (estatística $\tau$ ) rejeita a hipótese nula de que não há cointegração, mesmo assim somente a 10\% de significância (ver Tabela 2).

\footnotetext{
${ }^{3} \mathrm{Na}$ verdade, a aplicação conjunta de testes de raiz unitária com hipóteses nulas distintas implicaria o uso de valores críticos modificados (Carrion-I-Silvestre et alii, 2001). Nesse sentido, mesmo com o uso dos valores modificados, o resultado de que as séries são $I(1)$ é confirmado.
} 
Figura 4: Histograma de $\left(\triangle P_{t}\right)$ e $\left(\triangle p_{t}\right)$
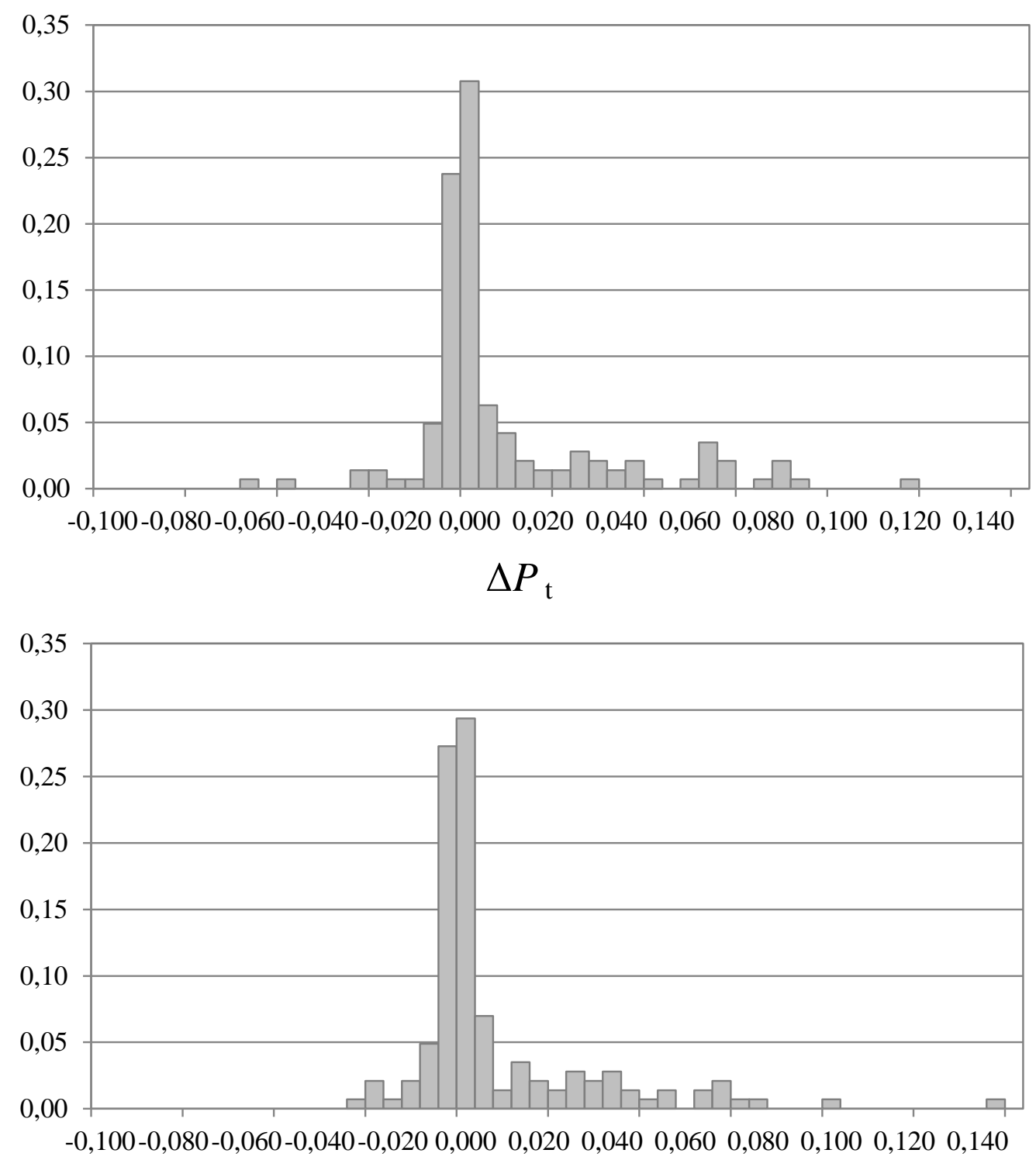

$\Delta p_{\mathrm{t}}$ 
Tabela 1: Testes de Raiz Unitária para as Séries de Interesse

\begin{tabular}{lcccc}
\hline & $P_{t}$ & $\triangle P_{t}$ & $p_{t}$ & $\triangle p_{t}$ \\
\hline Augmented Dickey-Fuller & $-2,307$ & $-6,927^{*}$ & $-1,841$ & $-6,765^{*}$ \\
& {$[1]$} & {$[1]$} & {$[1]$} & {$[0]$} \\
Phillips-Perron & $-2,146$ & $-6,268^{*}$ & $-1,655$ & $-6,768^{*}$ \\
& {$[4]$} & {$[6]$} & {$[4]$} & {$[2]$} \\
KPSS & $0,349^{*}$ & - & $0,353^{*}$ & - \\
& {$[9]$} & & {$[9]$} & \\
LS & $-4,344$ & - & -4.471 & - \\
& {$[1]$} & & {$[4]$} & \\
\hline
\end{tabular}

Para o KPSS a hipótese nula é de ausência de raiz unitária. Para os demais a hipótese nula é a de presença de raiz unitária. Para as séries em nível foram incluídas constante e tendência, para as primeiras diferenças apenas a constante. Entre colchetes o número de defasagens incluídas (para o Augmented Dickey-Fuller) ou o tamanho da janela escolhida (para o Phillips-Perron e o KPSS). 0 número de defasagens foi escolhido pela minimização do critério de informação de Schwarz e a janela pelo critério de Newey-West. Os símbolos *, ** e ${ }^{* * *}$ indicam rejeição da hipótese nula a 1\%,5\% e $10 \%$ de significância, respectivamente. Os valores críticos das estatísticas-teste para o Augmented Dickey-Fuller e o Phillips-Perron são -4,028 (1\%), -3,444 (5\%) e -3,147 (10\%) para o modelo com tendência e constante e -3,480 (1\%), -2,883 (5\%) e -2,578 (10\%) para o modelo apenas com constante. Para KPSS os valores são $-0,216(1 \%), 0,146(5 \%)$ e 0,119 (10\%) para o modelo com tendência e constante. Para o LS os valores são $-6,281(1 \%),-5,620$ (5\%) e -5,247 (10\%), referente ao modelo com duas quebras endógenas na constante e na tendência. No teste LS as quebras estruturais foram estimadas em 11/2003 e 05/2005 para os preços no atacado e em 12/2000 e 09/2002 para os preços no varejo. 
No entanto, assim como nos testes de raiz unitária, é sabido que a presença de quebras estruturais nas séries também pode viesar os testes de cointegração [ver Madalla e Kim (1998) para referências]. A esse respeito, Cook e Vougas (2007) mostram que o teste de cointegração proposto em Cook e Vougas (2008) é robusto à presença de quebras estruturais nas séries. A aplicação desse teste nas variáveis de interesse confirma a cointegração entre elas (ver Tabela 2). Sendo assim, é possível a estimação do mecanismo de transmissão dos preços como um modelo de correção de erros. Na verdade, esse resultado era esperado e mostra-se bastante intuitivo. Dada a presença de raiz unitária nas séries de interesse, se não houvesse cointegração, as diferenças na transmissão dos preços entre choques positivos e negativos seriam permanentes e os preços no varejo e no atacado poderiam se afastar indefinidamente (Meyer e Von Cramon Taubadel, 2004). ${ }^{4}$

Tabela 2: Testes de Cointegração entre $P_{t}$ e $p_{t}$

\begin{tabular}{lc}
\hline & Estatística-Teste \\
\hline Engle-Granger (Estatística $\tau$ ) & $-3,136[0,080]$ \\
Engle-Granger (Estatística $z$ ) & $-14,881[0,139]$ \\
Johansen (Traço) & $11,511[0,182]$ \\
Johansen (Máximo Autovalor) & $8,542[0,326]$ \\
Cook-Vougas & $-6,418[0,000]$ \\
\hline Para todos os testes a hipótese nula é de ausência de cointegração. \\
Entre colchetes são apresentados os $p$-valores. \\
O teste de Cook-Vougas é robusto à presença de quebras estruturais nas séries.
\end{tabular}

Por fim, ressalte-se que há evidências de que o preço do diesel no atacado causa, no sentido de Granger, o preço no varejo, mas não o contrário (ver Tabela 3). ${ }^{5}$ Embora não seja evidência definitiva, este resultado é indício de que não há causalidade reversa (do varejo para o atacado) na transmissão dos preços do óleo diesel. Este tema será retomado na Seção 4.

Tabela 3: Testes de Causalidade de Granger

\begin{tabular}{lcc}
\hline Defasagens & $H_{0}: \triangle P_{t}$ não Granger-Causa $H_{0}: \triangle p_{t}$ & $H_{0}: \triangle p_{t}$ não Granger-Causa $\triangle P_{t}$ \\
\hline 1 & $10,600[0,001]$ & $0,220[0,640]$ \\
2 & $5,500[0,005]$ & $0,244[0,784]$ \\
3 & $2,159[0,096]$ & $0,649[0,585]$ \\
4 & $2,089[0,086]$ & $0,520[0,721]$ \\
\hline
\end{tabular}

Entre colchetes são apresentados os $p$-valores.

\footnotetext{
${ }^{4}$ Eventualmente, onze anos poderia ser considerada uma amostra muito pequena para se trabalhar com equilíbrio de longo prazo. No entanto, boa parte da literatura sobre assimetria na transmissão de preços usa amostras de tamanhos similares [ver Meyer e Von Cramon Taubadel (2004), Frey e Manera (2007) para evidências a esse respeito].

${ }^{5}$ Somente foram apresentados os testes até quatro defasagens, mas os resultados são robustos à inclusão de defasagens adicionais.
} 


\section{RESULTADOS}

\subsection{Testes de assimetria}

A Tabela 4 apresenta os resultados para quatro diferentes versões do modelo explicitado em (1). 0 ajuste foi satisfatório $\left(R^{2} \geq 0,85\right)$. Ademais, as variáveis mais importantes se mostraram significativas e apresentaram o sinal esperado. Conforme salientado, as estimativas de $\delta$ e $\lambda$ foram usadas como parâmetros conhecidos na estimação de (1). A esse respeito, note-se que o vetor de cointegração estimado indica que no longo prazo quase $100 \%$ dos choques no preço do óleo diesel no atacado são transferidos para o varejo $(\lambda=0,943)$. Tal resultado confirma as evidências preliminares apresentadas na seção 3 (ver Figura 2).

Saliente-se também que o número de defasagens das variáveis explicativas foi escolhido de modo a minimizar o critério de informação de Schwarz. Nesse sentido, além do número de defasagens escolhido, a diferença entre as especificações (A1) e (B1) é basicamente à inclusão (ou não) de parâmetros de ajuste de longo prazo $(\theta)$ diferentes para quando o preço no varejo se encontra acima $\left(\theta^{+}\right)$ou abaixo $\left(\theta^{-}\right)$do equilíbrio. As especificações (C1) e (D1) retomam as especificações (A1) e (B1) com a inclusão de variáveis dummies sazonais para cada mês do ano (a referência é o mês de janeiro). Por sua vez, as especificações (E1) e (F1) não incluem o termo de correção de erro. Os testes de especificação também indicam que os erros não apresentam autocorrelação serial e que se comportam como um ruído branco.

Além disso, o modelo apresentado em (1) poderia conter variáveis endógenas, em particular se determinantes não observáveis do preço no varejo também estivessem correlacionados com o preço no atacado (Boreinstein et alii, 1997). Nesse caso, esta última variável poderia estar correlacionada com o termo de erro.

Para contornar esse problema, o preço do óleo diesel no atacado nos Estados Unidos e o preço do petróleo no mercado futuro norte-americano foram usados como instrumentos. ${ }^{6}$ Ambos são correlacionados com o preço no atacado do óleo diesel no Brasil, mas não são afetados por choques na demanda brasileira pelo combustível. No entanto, os testes de endogeneidade indicam que a variação contemporânea (positiva e negativa) do preço no atacado pode ser considerada exógena em todas as especificações estimadas (ver Tabela 4). Desse modo, o uso de mínimos quadrados ordinários na estimação dos parâmetros de interesse gera estimativas consistentes e é relativamente mais eficiente do que estimadores que usam variáveis instrumentais.

Os resultados são semelhantes para todas as especificações. Nota-se que não é possível rejeitar a hipótese nula de que os parâmetros $\theta^{+}$e $\theta^{-}$são iguais. Além disso, as dummies sazonais não se mostram conjuntamente significativas. Desse modo, optou-se por analisar com mais detalhes os resultados da especificação (B1). Aliás, como $\theta^{+} \neq \theta^{-}$não se confirma a existência de $A T A E$.

Percebe-se que o ajuste contemporâneo de choques positivos nos preços do óleo diesel no atacado é maior do que quando o choque é negativo. Basicamente, quando o choque é positivo o ajuste é praticamente instantâneo $\left(\beta_{0}^{+}=0,922\right)$ enquanto o mesmo não corre em caso de choques negativos $\left(\beta_{0}^{-}=0,365\right)$. O teste de significância confirma este resultado, indicando que não é possível aceitar a hipótese nula de que $\beta_{0}^{+}=\beta_{0}^{-}$. Em outras palavras, confirma-se a existência de $A I C$. Ademais, como o preço no atacado somente entra como variável explicativa de forma contemporânea $\left(J^{+}=J^{-}=0\right)$, automaticamente confirma-se a ocorrência de $A E D$ e $A I A$.

Finalmente, com relação à $A T R$, convém construir a função de ajuste cumulativo a partir de (1). Supondo-se $\theta^{+}=\theta^{-}$, o que é mais adequado dada a escolha da especificação (B1), não é difícil mostrar que, após um choque positivo de $1 \%$ no preço do óleo diesel no atacado, o impacto acumulado no preço do combustível no varejo após $t$ períodos $\left(B_{t}^{+}\right)$é definido por (Boreinstein et alii, 1997):

\footnotetext{
${ }^{6}$ Ambas as séries foram extraídas da página da Energy Information Administration (EIA), diferenciadas e desmembradas em suas versões positivas e negativas, como as demais variáveis utilizadas. Trata-se de estratégia semelhante à utilizada em Boreinstein et alii (1997).
} 
Tabela 4: Modelo de Transmissão de Preços - Parâmetros Estimados

\begin{tabular}{|c|c|c|c|c|c|c|}
\hline & (A1) & (B1) & (C1) & (D1) & (E1) & (F1) \\
\hline \multirow[t]{2}{*}{$\alpha$} & 0,000 & $-0,001$ & $-0,003$ & $-0,004$ & 0,000 & 0,004 \\
\hline & $(-0,002)$ & $(-0,001)$ & $(-0,003)$ & $(-0,003)$ & $(-0,001)$ & $(-0,003)$ \\
\hline \multirow[t]{2}{*}{$\beta_{0}^{+}$} & $0,954^{*}$ & $0,922^{*}$ & $0,961^{*}$ & $0,918^{*}$ & $0,934^{*}$ & $0,899^{*}$ \\
\hline & $(-0,057)$ & $(-0,063)$ & $(-0,050)$ & $(-0,060)$ & $(-0,067)$ & $(-0,064)$ \\
\hline \multirow[t]{2}{*}{$\beta_{0}^{-}$} & $0,381^{*}$ & $0,365^{*}$ & $0,377^{*}$ & $0,353^{*}$ & $0,386^{*}$ & $0,371^{*}$ \\
\hline & $(0,000)$ & $(-0,063)$ & $(-0,059)$ & $(-0,068)$ & $(-0,058)$ & $(-0,064)$ \\
\hline \multirow[t]{2}{*}{$\gamma_{1}^{+}$} & $-0,070$ & $-0,025$ & $-0,065$ & $-0,013$ & $-0,041$ & $-0,030$ \\
\hline & $(-0,064)$ & $(-0,060)$ & $(-0,064)$ & $(-0,056)$ & $(-0,057)$ & $(-0,052)$ \\
\hline \multirow[t]{2}{*}{$\gamma_{1}^{-}$} & 0,062 & 0,106 & 0,005 & 0,093 & 0,291 & 0,296 \\
\hline & $(-0,149)$ & $(-0,157)$ & $(-0,158)$ & $(-0,156)$ & $(-0,182)$ & $(-0,188)$ \\
\hline \multirow[t]{2}{*}{$\gamma_{2}^{+}$} & 0,077 & - & 0,081 & - & - & - \\
\hline & $(-0,050)$ & & $(-0,053)$ & & & \\
\hline \multirow[t]{2}{*}{$\theta^{+}$} & $-0,175^{* *}$ & - & $-0,172^{* *}$ & - & - & - \\
\hline & $(-0,083)$ & & $(-0,076)$ & & & \\
\hline \multirow[t]{2}{*}{$\theta^{-}$} & $-0,015$ & - & $-0,018$ & - & - & - \\
\hline & $(-0,052)$ & & $(-0,061)$ & & & \\
\hline \multirow[t]{2}{*}{$\theta$} & - & $-0,114^{*}$ & - & $-0,111^{*}$ & - & - \\
\hline & & $-0,042$ & & $-0,041$ & & \\
\hline \multirow[t]{2}{*}{$\delta$} & $0,201^{*}$ & $0,201^{*}$ & $0,201^{*}$ & $0,201^{*}$ & - & - \\
\hline & $(-0,054)$ & $(-0,054)$ & $(-0,054)$ & $(-0,054)$ & & \\
\hline \multirow[t]{2}{*}{$\lambda$} & $0,943^{*}$ & $0,943^{*}$ & $0,943^{*}$ & $0,943^{*}$ & - & - \\
\hline & $(-0,009)$ & $(-0,009)$ & $(-0,009)$ & $(-0,009)$ & & \\
\hline Dummies sazonais & Não & Não & Sim & Sim & Não & Sim \\
\hline \multirow[t]{2}{*}{ Significância das dummies sazonais } & - & - & 1,558 & 0,756 & - & 0,802 \\
\hline & & & {$[0,121]$} & {$[0,683]$} & & {$[0,638]$} \\
\hline \multirow[t]{2}{*}{$\beta_{0}^{+}=\beta_{0}^{-}$} & 6,204 & 5,687 & 7,039 & 5,896 & 5,283 & 5,449 \\
\hline & {$[0,000]$} & {$[0,000]$} & {$[0,000]$} & {$[0,001]$} & {$[0,000]$} & {$[0,000]$} \\
\hline \multirow[t]{2}{*}{$\theta^{+}=\theta^{-}$} & $-1,356$ & - & $-1,312$ & - & - & - \\
\hline & {$[0,178]$} & & {$[0,192]$} & & & \\
\hline \multirow[t]{2}{*}{ Teste LM de correlação serial } & 0,483 & 0,661 & 0,571 & 0,906 & 1,476 & 1,654 \\
\hline & {$[0,612]$} & {$[0,518]$} & {$[0,567]$} & {$[0,407]$} & {$[0,233]$} & {$[0,196]$} \\
\hline \multirow[t]{2}{*}{ Teste de endogeneidade } & 0,917 & 1,075 & 0,217 & 0,475 & 0,646 & 0,263 \\
\hline & {$[0,632]$} & {$[0,584]$} & {$[0,897]$} & {$[0,789]$} & {$[0,724]$} & {$[0,877]$} \\
\hline$R^{2}$ & 0,880 & 0,859 & 0,892 & 0,866 & 0,847 & 0,856 \\
\hline Número de observações & 132 & 133 & 132 & 133 & 133 & 133 \\
\hline
\end{tabular}

Os símbolos *, ${ }^{* *} \mathrm{e}^{* * *}$ indicam significância a 1\%, 5\% e 10\%, respectivamente. Entre parênteses os desvios-padrão das estimativas, calculados a partir de matriz de covariância robusta à heterocedasticidade e correlação serial (Newey e West, 1987). Entre colchetes os $p$-valores. O número de defasagens das variáveis explicativas foi escolhido de modo a minimizar o critério de informação de Schwarz. As estimativas das dummies sazonais foram omitidas por conveniência. O teste de correlação serial é um teste LM cuja hipótese nula é de ausência de autocorrelação até o $i$-ésimo defasagem. Os valores reportados são para $i=2$, mas os resultados são robustos ao uso de outras defasagens. As estatísticas $Q$ de $L j u n g-B o x$ (não reportadas para economizar espaço) indicam que os erros são ruídos brancos. O teste de endogeneidade se refere ao teste Durbin-Wu-Hausman da hipótese nula de consistência do estimador de mínimos quadrados ordinários [ver Davidson e Mackinnon (1993, p. 237-242) para detalhes]. 


$$
\begin{aligned}
& B_{0}^{+}=\beta_{0}^{+}, \\
& B_{1}^{+}=B_{0}^{+}+\beta_{1}^{+}+\theta\left(B_{0}^{+}-\lambda\right)+\gamma_{1}^{+} \max \left(0, B_{0}^{+}\right)+\gamma_{1}^{-} \min \left(0, B_{0}^{+}\right), \\
& B_{2}^{+}=B_{1}^{+}+\beta_{2}^{+}+\theta\left(B_{1}^{+}-\lambda\right)+\gamma_{1}^{+} \max \left(0, B_{1}^{+}-B_{0}^{+}\right)+\gamma_{1}^{-} \min \left(0, B_{1}^{+}-B_{0}^{+}\right) \\
& +\gamma_{2}^{+} \max \left(0, B_{0}^{+}\right)+\gamma_{2}^{-} \min \left(0, B_{0}^{+}\right) \text {, } \\
& \begin{array}{cc}
\vdots & \vdots \\
B_{t}^{+}= & B_{t-1}^{+}+\beta_{t}^{+}+\theta\left(B_{t-1}^{+}-\lambda\right)+\sum_{i=1}^{t-1}\left[\gamma_{i}^{+} \max \left(0, B_{t-1}^{+}-B_{t-i-1}^{+}\right)\right.
\end{array} \\
& \left.+\gamma_{i}^{-} \min \left(0, B_{t-i}^{+}-B_{t-i-1}^{+}\right)\right] \\
& +\gamma_{t}^{+} \max \left(0, B_{0}^{+}\right)+\gamma_{t}^{-} \min \left(0, B_{0}^{+}\right)
\end{aligned}
$$

Ou seja, o impacto acumulado após $t$ períodos é a soma:

(i) do impacto acumulado até o período anterior $\left(B_{t-1}^{+}\right)$;

(ii) do impacto contemporâneo do preço no atacado no mês $t\left(\beta_{t}^{+}\right)$;

(iii) do efeito de se estar fora do equilíbrio de longo prazo, associado ao termo de correção de erros $\left[\theta\left(B_{t-1}^{+}-\lambda\right)\right]$

(iv) dos efeitos das mudanças passadas no preço do varejo [restante da expressão em (2)].

A função de ajuste cumulativo para choques negativos é análoga.

A Figura 5 apresenta o impacto acumulado após choques positivos e negativos de $1 \%$ no preço do óleo diesel no atacado. Mais uma vez, nota-se que o ajuste após uma variação positiva no preço no atacado é bastante rápido e está praticamente completo ainda no mês do choque.

Figura 5: Impacto Acumulado (Após Variação de 1\% do Preço no Atacado)

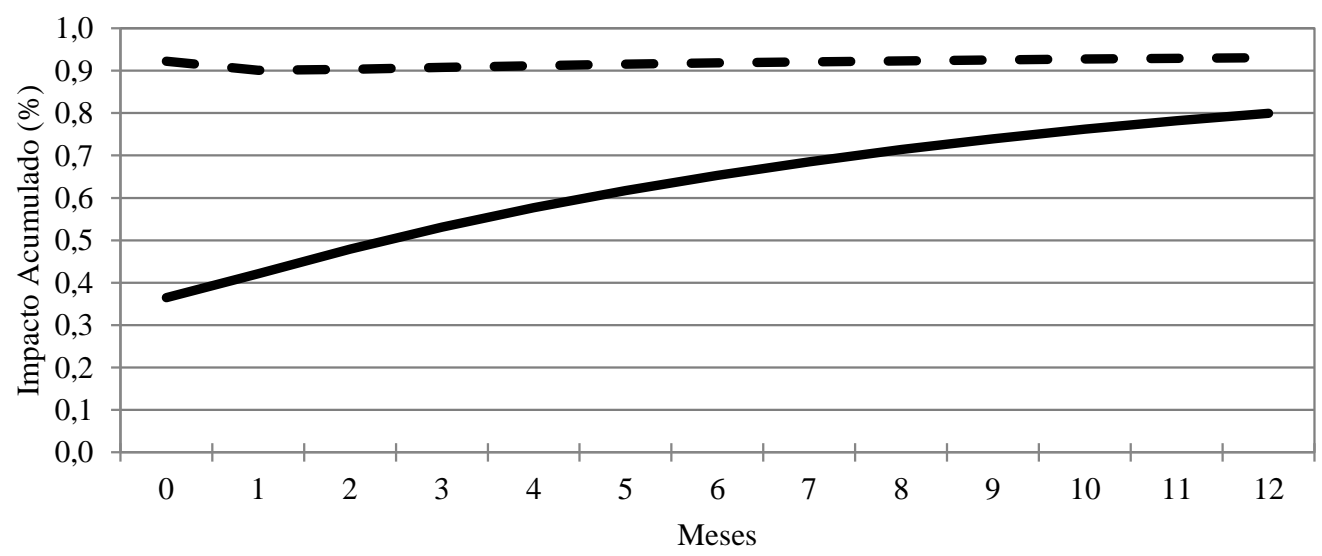

$\longrightarrow$ Redução de $1 \% \quad-$ - Aumento de $1 \%$

No entanto, o ajuste em resposta a choques negativos é bem mais lento. No mês do choque o impacto acumulado é de $0,922 \%$ em caso de choque positivo e $0,365 \%$ em caso de choque negativo. 
No mês seguinte o impacto acumulado é de $0,901 \%$ e $0,421 \%$, respectivamente. A Tabela 5 indica que somente a partir do $12^{\circ}$ mês a diferença entre o impacto acumulado de choques positivos e negativos $\left(B_{t}^{+}-B_{t}^{-}\right)$passa a ser significativamente nula do ponto de vista estatístico. O mesmo resultado pode ser visto na Figura 6. Em resumo, há fortes evidências da existência de $A T R$.

Figura 6: Assimetria no Impacto Acumulado (Após Variação de 1\% do Preço no Atacado)

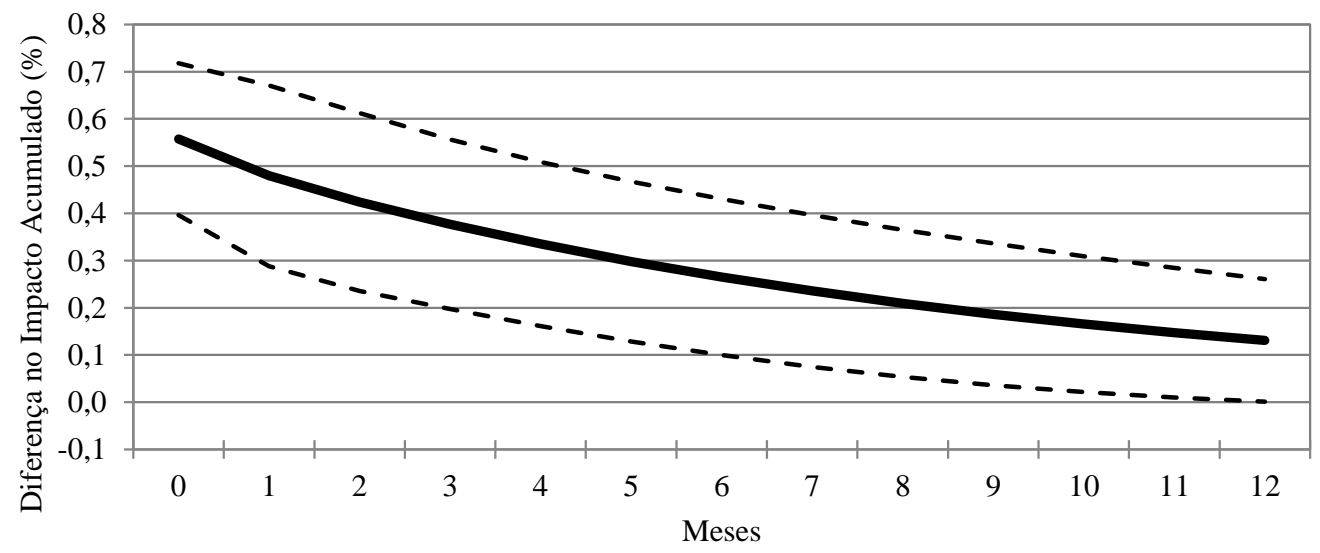

$\longrightarrow$ Assimetria _ - - Intervalo de Confiança (90\%)

Tabela 5: Testes para $A T R$

\begin{tabular}{cccccccccc}
\hline & $t=0$ & $t=1$ & $t=2$ & $t=3$ & $\cdots$ & $t=9$ & $t=10$ & $t=11$ & $t=12$ \\
\hline$B_{t}^{+}-B_{t}^{-}$ & $0,557^{*}$ & $0,479^{*}$ & $0,424^{*}$ & $0,377^{*}$ & $\cdots$ & $0,186^{* *}$ & $0,166^{* * *}$ & $0,147^{* * *}$ & 0,131 \\
& $(0,098)$ & $(0,117)$ & $(0,115)$ & $(0,105)$ & & $(0,092)$ & $(0,088)$ & $(0,084)$ & $(0,079)$ \\
\hline
\end{tabular}

Os símbolos *,** ${ }^{* * *}$ indicam significância a $1 \%, 5 \%$ e $10 \%$, respectivamente.

Entre parênteses os desvios-padrão das estimativas, calculados a partir do método Delta [ver Greene (2000, p. 118)].

Por fim, convém explorar brevemente os modelos (E1) e (F1), estimados sem a inclusão do termo de correção de erro. São os modelos mais adequados se não existir relação de longo prazo entre os preços do óleo diesel no atacado e no varejo. Isso pode ocorrer, por exemplo, se as séries dos preços em nível forem estacionárias, e não $I(1)$, como apontado pelos testes de raiz unitária (ver Tabela 2). Obviamente não faz sentido falar de $A T A E$, pois não há equilíbrio de longo prazo para o qual convergir. Do ponto de vista das assimetrias de curto prazo, novamente é confirmada a existência de $A I C$ : hipótese nula de que $\beta_{0}^{+}=\beta_{0}^{-}$não é aceita. Aliás, os valores de $\beta_{0}^{+}$e $\beta_{0}^{-}$sofreram pouca alteração se comparados aos demais modelos. Ademais, como $J^{+}=J^{-}=0$, automaticamente confirma-se a ocorrência de $A E D$ e $A I A$. Por fim, conforme já salientado, a ausência do termo de correção de erro significa que as diferenças dos impactos de choques positivos e negativos tendem a se perpetuar no longo prazo (ver Figura 7), o que implica a confirmação de $A T R$. Em suma, os resultados - assimetrias na transmissão dos preços no curto e no longo prazo - são robustos à exclusão do termo de correção de erro. 
Figura 7: Impacto Acumulado (Após Variação de 1\% do Preço no Atacado) - Modelo (E1)

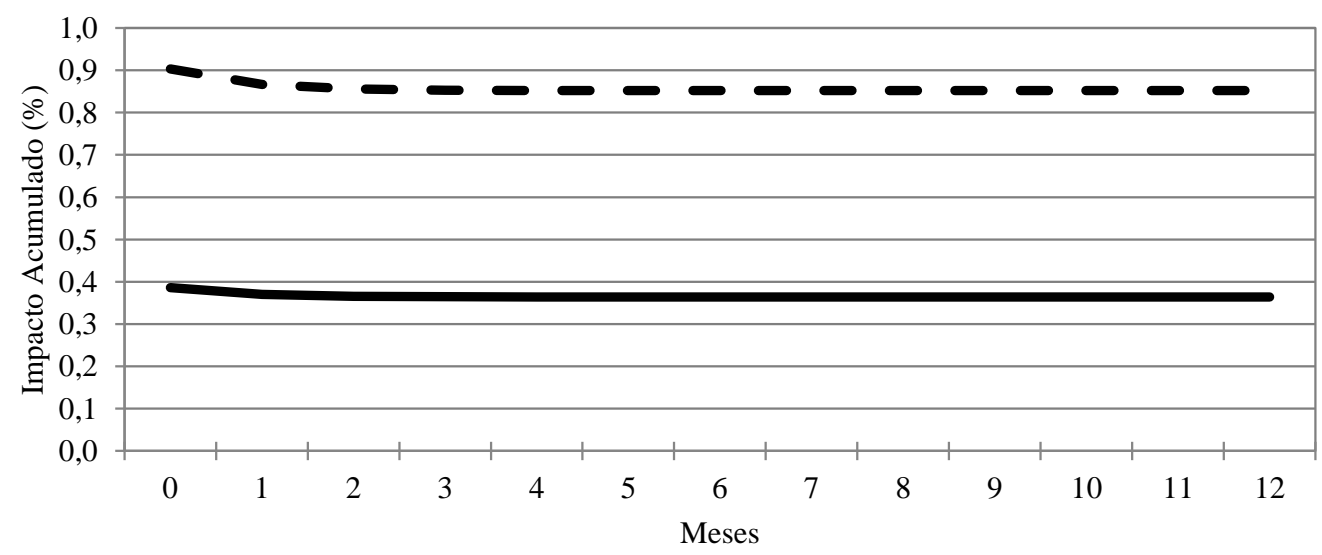

$\longrightarrow$ Redução de $1 \% \quad-$ Aumento de $1 \%$

\subsection{Testes de assimetria e quebras estruturais}

Experimentos demonstram que, na presença de quebras estruturais no vetor de cointegração, os testes de assimetria tendem a rejeitar de forma espúria a hipótese nula de simetria na transmissão dos preços (Von Cramon Taubadel e Meyer, 2001). A aplicação dos procedimentos propostos em Bai e Perron (1998) indicam que, de fato, o vetor de cointegração entre os preços do óleo diesel no varejo e no atacado possui quebras estruturais. Nesse caso, convém verificar se as evidências de assimetria encontradas são robustas à presença dessas quebras.

Nesse sentido, a Tabela 6 apresenta os resultados da estimação dos parâmetros de interesse do modelo levando-se em consideração a presença de quebras estruturais. O procedimento é análogo, a única diferença se refere à estimação do vetor de cointegração incorporando-se - pela inclusão de variáveis binárias - as quebras estruturais identificadas pelo método de Bai e Perron (1998). ${ }^{7}$ Salvo por mudanças nas defasagens das variáveis (e nas quebras estruturais do vetor de cointegração, obviamente), as especificações (A2), (B2), (C2) e (D2) se referem exatamente às especificações (A1), (B1), (C1) e (D1) da Tabela 4.

Os resultados apresentados se referem somente a mudanças no intercepto, mas as conclusões não se alteram significativamente quando são permitidas mudanças somente na inclinação ou em ambos os parâmetros. A propósito, foram identificadas três quebras estruturais, em agosto de 2001, julho de 2003 e junho de 2008. Além disso, os resultados não se alteram qualitativamente no que se refere à ausência de autocorrelação serial nos resíduos e exogeneidade dos preços no atacado. No entanto, notam-se algumas mudanças:

(i) a estimativa do parâmetro $\lambda$ diminuiu, o que significa um repasse menor no longo prazo;

\footnotetext{
${ }^{7}$ Nesse ponto vale ressaltar que o método permite testar a presença e estimar as datas de ocorrência de quebras estruturais em datas desconhecidas. Ou seja, não se impõe de antemão a quantidade de quebras, tampouco as datas de ocorrência das mesmas. Mais detalhes ver Apêndice.
} 
Tabela 6: Modelo de Transmissão de Preços - Parâmetros Estimados com Quebras Estruturais no Vetor de Cointegração

\begin{tabular}{|c|c|c|c|c|}
\hline & (A2) & (B2) & (C2) & (D2) \\
\hline \multirow[t]{2}{*}{$\alpha$} & $-0,001$ & $-0,001$ & $-0,004$ & $-0,004$ \\
\hline & $(-0,001)$ & $(-0,001)$ & $(-0,003)$ & $(-0,003)$ \\
\hline \multirow[t]{2}{*}{$\beta_{0}^{+}$} & $0,945^{*}$ & $0,915^{*}$ & $0,949^{*}$ & $0,947^{*}$ \\
\hline & $(-0,050)$ & $(-0,056)$ & $(-0,044)$ & $(-0,045)$ \\
\hline \multirow[t]{2}{*}{$\beta_{0}^{-}$} & $0,374^{*}$ & $0,375^{*}$ & $0,380^{*}$ & $0,391^{*}$ \\
\hline & $(-0,083)$ & $(-0,056)$ & $(-0,083)$ & $(-0,078)$ \\
\hline \multirow{2}{*}{$\gamma_{1}^{+}$} & $-0,055$ & $-0,018$ & $-0,046$ & $-0,058$ \\
\hline & $(-0,059)$ & $(-0,055)$ & $(-0,056)$ & $(-0,058)$ \\
\hline \multirow[t]{2}{*}{$\gamma_{1}^{-}$} & $-0,084$ & 0,001 & $-0,197$ & $-0,065$ \\
\hline & $(-0,146)$ & $(-0,110)$ & $(-0,188)$ & $(-0,121)$ \\
\hline \multirow[t]{2}{*}{$\gamma_{2}^{+}$} & 0,076 & - & $0,089^{* * *}$ & 0,078 \\
\hline & $(-0,051)$ & & $(-0,052)$ & $(-0,053)$ \\
\hline \multirow[t]{2}{*}{$\theta^{+}$} & $-0,336^{*}$ & - & $-0,376^{*}$ & - \\
\hline & $(-0,097)$ & & $(-0,114)$ & \\
\hline \multirow[t]{2}{*}{$\theta^{-}$} & $-0,186^{*}$ & - & $-0,167^{*}$ & - \\
\hline & $(-0,050)$ & & $(-0,063)$ & \\
\hline \multirow[t]{2}{*}{$\theta$} & - & $-0,273^{*}$ & - & $-0,253^{*}$ \\
\hline & & $(-0,049)$ & & $(-0,039)$ \\
\hline \multirow[t]{2}{*}{$\lambda$} & $0,864^{*}$ & $0,864^{*}$ & $0,864^{*}$ & $0,864^{*}$ \\
\hline & $(-0,023)$ & $(-0,023)$ & $(-0,023)$ & $(-0,023)$ \\
\hline Dummies sazonais & Não & Não & Sim & $\operatorname{Sim}$ \\
\hline \multirow[t]{2}{*}{ Significância das dummies sazonais } & - & - & 1,663 & 1,799 \\
\hline & & & {$[0,091]$} & {$[0,062]$} \\
\hline Quebras no vetor de cointegração & $\operatorname{Sim}$ & $\operatorname{Sim}$ & Sim & Sim \\
\hline \multirow[t]{3}{*}{ Datas estimadas das quebras } & ago/01 & ago/01 & ago/01 & ago/01 \\
\hline & jul/03 & jul/03 & jul/03 & $\mathrm{jul} / 03$ \\
\hline & jun/08 & jun/08 & jun/08 & jun $/ 08$ \\
\hline \multirow[t]{2}{*}{$\beta_{0}^{+}=\beta_{0}^{-}$} & 5,803 & 5,412 & 6,074 & 6,194 \\
\hline & {$[0,000]$} & {$[0,000]$} & {$[0,000]$} & {$[0,000]$} \\
\hline \multirow[t]{2}{*}{$\theta^{+}=\theta^{-}$} & $-1,175$ & - & $-1,331$ & - \\
\hline & {$[0,242]$} & & {$[0,186]$} & \\
\hline \multirow[t]{2}{*}{ Teste LM de correlação serial } & 0,726 & 0,503 & 0,592 & 1,073 \\
\hline & {$[0,486]$} & {$[0,606]$} & {$[0,555]$} & {$[0,346]$} \\
\hline \multirow[t]{2}{*}{ Teste de endogeneidade } & 1,382 & 2,483 & 2,013 & 2,261 \\
\hline & {$[0,501]$} & {$[0,289]$} & {$[0,366]$} & {$[0,323]$} \\
\hline$R^{2}$ & 0,898 & 0,879 & 0,909 & 0,907 \\
\hline Número de observações & 132 & 133 & 132 & 132 \\
\hline
\end{tabular}

Os símbolos *, * $\mathrm{e}^{* * *}$ indicam significância a 1\%,5\% e 10\%, respectivamente. Entre parênteses os desvios-padrão das estimativas, calculados a partir de matriz de covariância robusta à heterocedasticidade e correlação serial (Newey e West, 1987). Entre colchetes os $p$-valores. O número de defasagens das variáveis explicativas foi escolhido de modo a minimizar o critério de informação de Schwarz. As estimativas das dummies sazonais e dos diferentes interceptos do vetor de cointegração foram omitidas por conveniência. Datas das quebras estruturais estimadas pelo procedimento de Bai e Perron (1998) [mais detalhes ver Apêndice]. O teste de correlação serial é um teste LM cuja hipótese nula é de ausência de autocorrelação até o $i$-ésimo defasagem. Os valores reportados são para $i=2$, mas os resultados são robustos ao uso de outras defasagens. As estatísticas $Q$ de Ljung-Box (não reportadas para economizar espaço) indicam que os erros são ruídos brancos. O teste de endogeneidade se refere ao teste Durbin-Wu-Hausman da hipótese nula de consistência do estimador de mínimos quadrados ordinários [ver Davidson e Mackinnon (1993, p. 237-242) para detalhes]. 
(ii) a estimativa do parâmetro $\theta$ (e de suas contrapartidas positivas e negativas) aumentou mais de duas vezes (em valor absoluto), o que indica uma maior velocidade de convergência para o equilíbrio de longo prazo;

(iii) os efeitos sazonais passaram a ter significância estatística, o que motivou a escolha do modelo (D1) como referência.

Apesar das mudanças, as conclusões com relação à existência de assimetria não mudaram. Ainda confirmam-se assimetrias no curto prazo ( $A I C$ e $A E D$ ) e no longo prazo ( $A I A$ e $A T R$ ), com exceção da $A T A E$ (a hipótese de igualdade entre $\theta^{+}$e $\theta^{-}$continua sendo aceita).

Quando o choque é positivo o ajuste contemporâneo continua sendo muito maior $\left(\beta_{0}^{+}=0,947\right)$ do que quando o choque é negativo $\left(\beta_{0}^{-}=0,391\right)$, indicando $A T R$ (e também $A E D$ e $A I A$, pois $J^{+}=J^{-}=0$ ). A Figura 8 deixa transparecer a maior velocidade de convergência: as curvas se aproximam mais rápido do que na Figura 5. Diferentemente do modelo sem quebras estruturais, o ajuste a choques positivos mostra-se mais claramente não-monótono nos primeiros meses. Este resultado é uma combinação da diferença no sinal entre $\gamma_{2}^{+}>0$ e $\gamma_{1}^{+}<0$ e da maior diferença entre o repasse contemporâneo $\left(\beta_{0}^{+}\right)$e o repasse de longo prazo $(\lambda)$.

A despeito da maior velocidade de convergência para o equilíbrio de longo prazo - visualizada pela diferença de inclinação das curvas apresentadas na Figura 6 e na Figura 9 - as estimativas apresentaram menor desvio-padrão (novamente, basta comparar a Figura $6 \mathrm{com}$ a Figura 9). Desse modo, a disparidade entre os impactos acumulados de choques positivos e negativos somente perde a significância estatística depois do décimo mês (ver Tabela 7), confirmando as fortes evidências de $A T R$.

Figura 8: Impacto Acumulado (Após Variação de 1\% do Preço no Atacado e com Quebras Estruturais no Vetor de Cointegração)

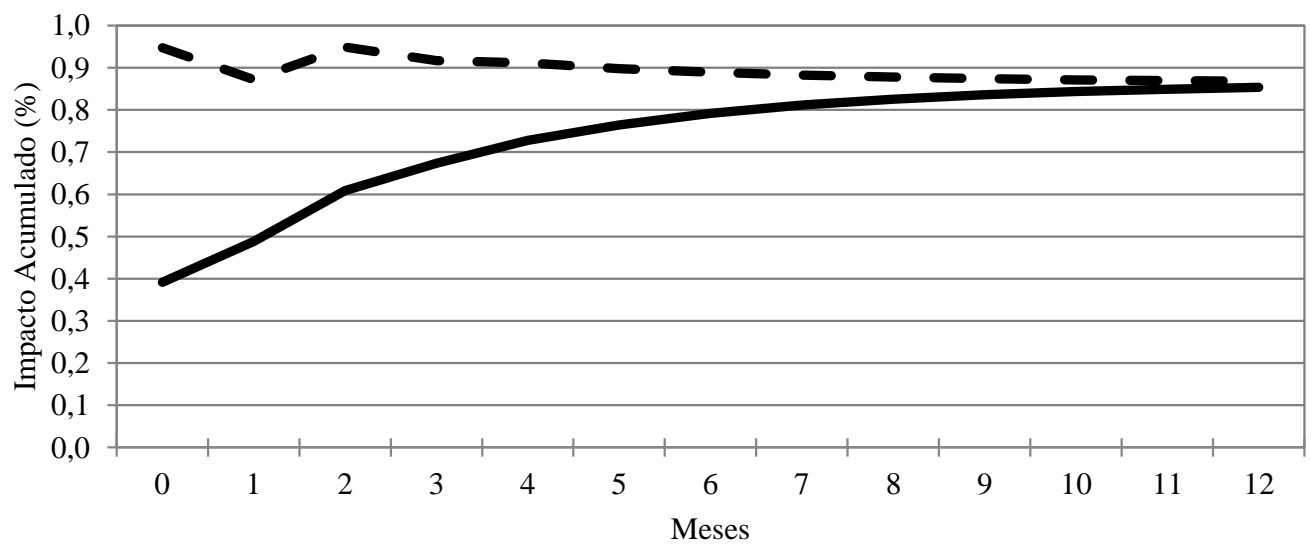

$$
\longrightarrow \text { Redução de } 1 \% \quad-\text { Aumento de } 1 \%
$$

\subsection{Custo da assimetria para o consumidor}

Tão importante quanto verificar a significância estatística da assimetria é medir a sua relevância econômica, tarefa raramente colocada em prática na literatura sobre o tema (Meyer e Von Cramon 
Figura 9: Assimetria no Impacto Acumulado (Após Variação de 1\% do Preço no Atacado e com Quebras Estruturais no Vetor de Cointegração)

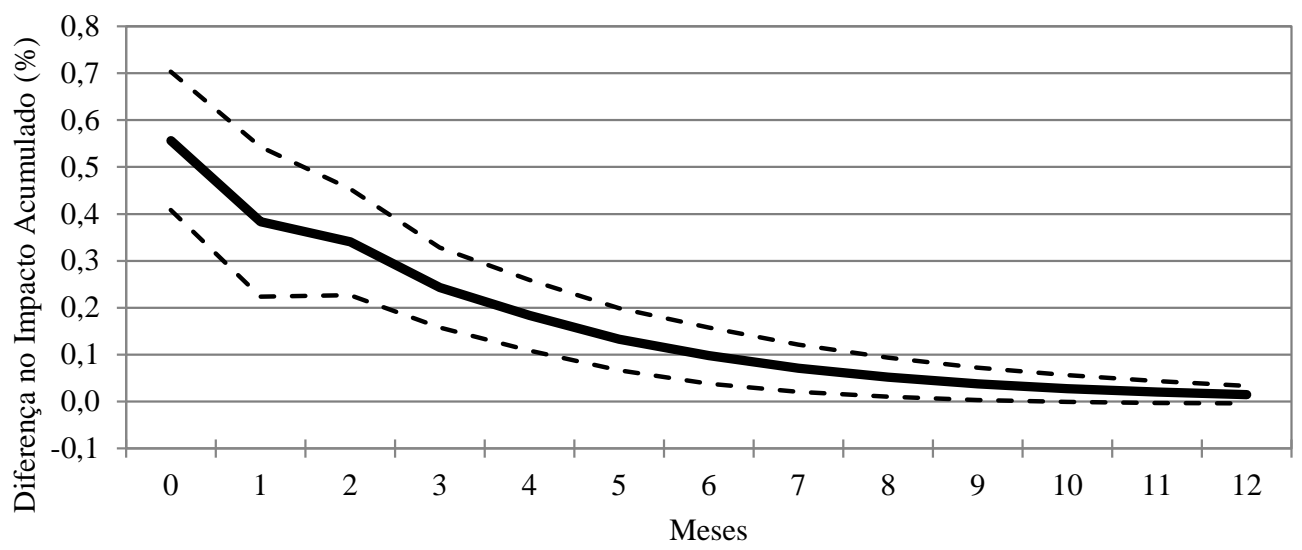

Assimetria $\quad$ - - - Intervalo de Confiança (90\%)

Tabela 7: Testes para $A T R$ (com Quebras Estruturais no Vetor de Cointegração)

\begin{tabular}{cccccccccc}
\hline & $t=0$ & $t=1$ & $t=2$ & $t=3$ & $\cdots$ & $t=9$ & $t=10$ & $t=11$ & $t=12$ \\
\hline$B_{t}^{+}-B_{t}^{-}$ & $0,556^{*}$ & $0,383^{*}$ & $0,340^{*}$ & $0,243^{*}$ & $\cdots$ & $0,038^{* * *}$ & 0,028 & 0,020 & 0,015 \\
& $(0,090)$ & $(0,097)$ & $(0,069)$ & $(0,052)$ & & $(0,021)$ & $(0,017)$ & $(0,014)$ & $(0,012)$ \\
\hline
\end{tabular}

Os símbolos *** e*** indicam significância a 1\%,5\% e 10\%, respectivamente.

Entre parênteses os desvios-padrão das estimativas, calculados a partir do método Delta [ver Greene (2000, p. 118)].

Taubadel, 2004). Nesse particular, mostra-se útil construir alguma medida das perdas associadas à assimetria na transmissão dos preços. Uma possibilidade é (Boreinstein et alii, 1997):

$$
A_{t}=\int_{i=0}^{t}\left(B_{i}^{+}-B_{i}^{-}\right) d i
$$

A medida apresentada em (3) nada mais é do que a diferença entre os ajustes acumulados resultantes de choques positivos e negativos. Mais especificamente, fazendo-se uma interpolação linear entre os ajustes acumulados estimados, $A_{t}$ pode ser calculado como a diferença entre as áreas sob as curvas apresentadas na Figura 6 e na Figura 9 entre os meses 0 e $t$ (Boreinstein et alii, 1997). Em termos econômicos, $A_{t}$ mede quanto que os consumidores gastariam a menos se os choques positivos fossem transmitidos da mesma forma que os negativos. Obviamente trata-se de uma medida imperfeita, pois não contempla o impacto nas quantidades demandadas.

A Figura 10 e a Figura 11 apresentam as estimativas de $A_{t}$ e seus intervalos de confiança para as duas especificações de referência [(B1) e (D2), sem e com quebras estruturais no vetor de cointegração, respectivamente]. As estimativas são apresentadas em termos percentuais do preço inicial (eixo da esquerda) e em unidades monetárias (eixo da direita), esta última calculada para o preço de $\mathrm{R} \$ 2,01$ por 
litro de óleo diesel no varejo, média brasileira na semana compreendida entre 10/07/2011 e 16/07/2011 de acordo com o levantamento de preços da ANP.

Se a consideração de quebras estruturais no vetor de cointegração não afeta substancialmente a significância estatística da assimetria, certamente altera a sua relevância econômica. Após doze meses, para a especificação sem quebras estruturais, o custo acumulado de um choque de $1 \%$ no preço no atacado é de R\$ 0,077 para cada litro de óleo diesel (3,81\% do preço no varejo), enquanto para o modelo com quebras é de R $\$, 043$ ( $2,16 \%$ do preço no varejo). Tomando-se o consumo brasileiro anual do produto em 2010, trata-se de aproximadamente $\mathrm{R} \$ 3,8$ bilhões por ano (ou R 2,1 bilhões para o modelo com quebras estruturais). ${ }^{8}$

Figura 10: Custo para o Consumidor

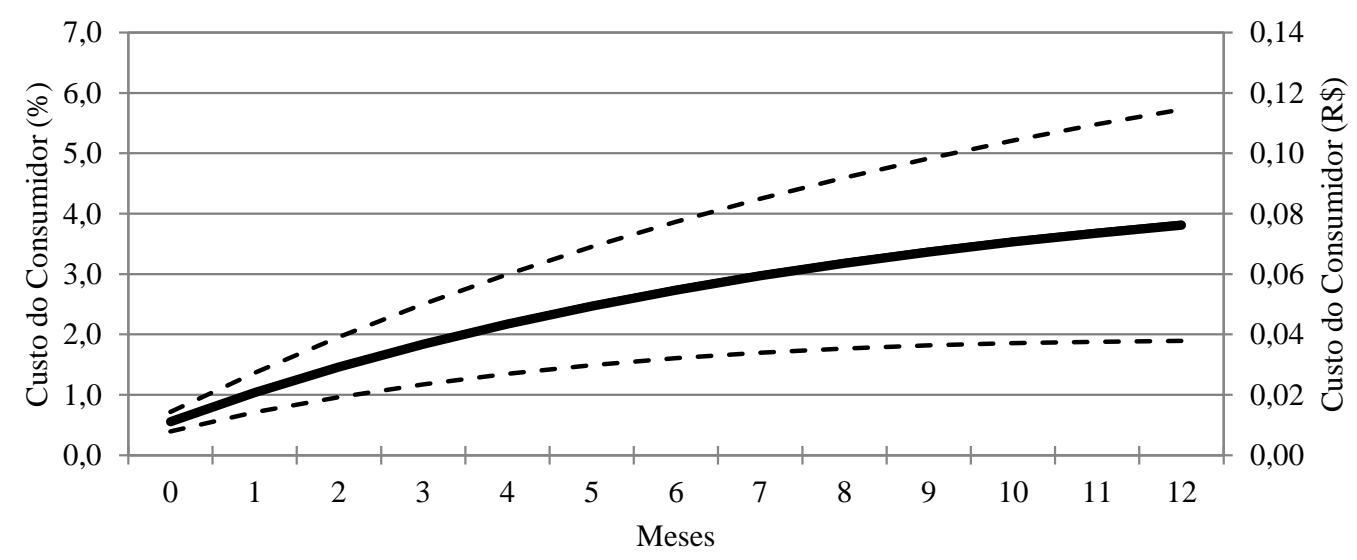

Custo do Consumidor $\quad$ - - - Intervalo de Confiança (90\%)

\subsection{Implicações para política pública}

A relevância estatística e econômica da assimetria na transmissão dos preços do óleo diesel no Brasil tem importantes implicações em termos de bem-estar e de política pública. A primeira delas se refere à distribuição de bem-estar distinta da que prevaleceria em caso de simetria. Conforme salientado na subseção 4.3 , para choques de $1 \%$ no preço no atacado trata-se de transferência de pelo menos $\mathrm{R} \$ 2,1$ bilhões por ano dos consumidores para os varejistas. Entretanto, dependendo das causas, a assimetria pode ter implicações em termos de perda de bem-estar (e não somente efeitos distributivos), em especial se são manifestações de falhas de mercado.

Nesse sentido, se a assimetria no repasse do preço do petróleo no mercado internacional para os preços da gasolina no varejo (Uchôa, 2007) pode ser facilmente explicada pela política de preços da Petrobras, que em várias oportunidades postergou o reajuste desse combustível, os motivos da assimetria no repasse do distribuidor para o varejo - objeto deste artigo - não são tão óbvios. ${ }^{9}$

\footnotetext{
${ }^{8}$ O consumo brasileiro em 2010 foi de 49,2 bilhões de litros de óleo diesel, segundo dados da ANP.

${ }^{9}$ As assimetrias encontradas são de natureza distinta das identificadas por Uchôa (2007), que encontra evidências de que o repasse de choques negativos é mais rápido do que de choques positivos. Note-se que em Uchôa (2007) as assimetrias se referem ao repasse do preço internacional do petróleo para os preços da gasolina ao consumidor final (e não do preço do óleo diesel no distribuidor para o varejo).
} 
Figura 11: Custo para o Consumidor (com Quebras Estruturais no Vetor de Cointegração)

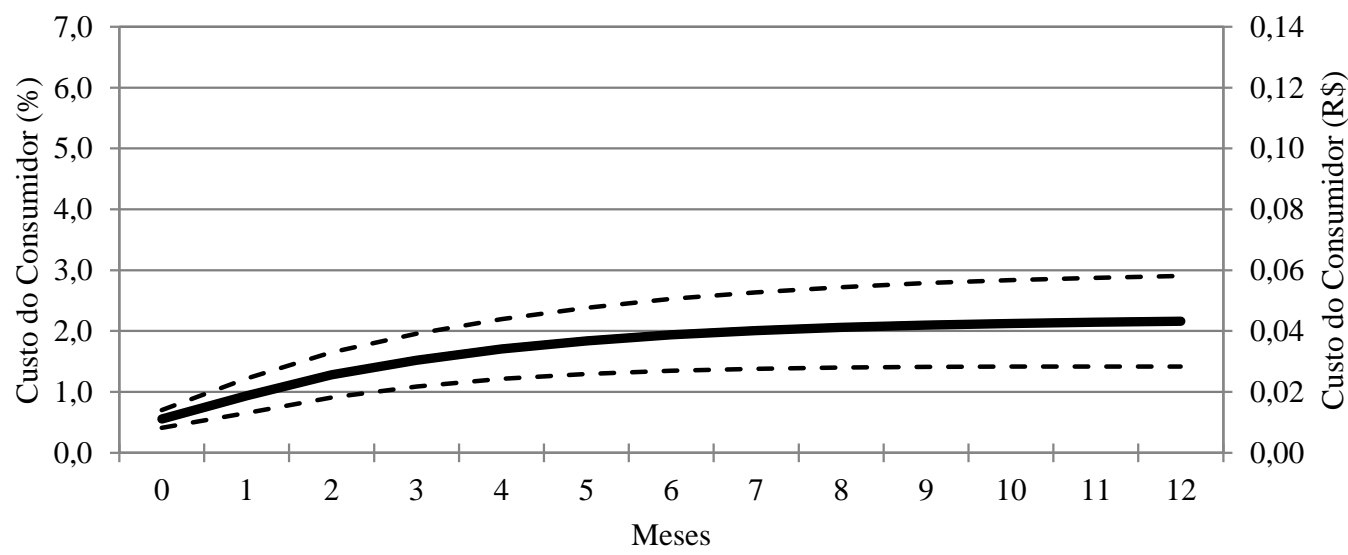

Custo do Consumidor _ _ - Intervalo de Confiança (90\%)

A esse respeito, a literatura aponta algumas possibilidades. Uma delas se refere à colusão dos varejistas na venda de combustíveis em torno de um preço focal (Boreinstein et alii, 1997). Considerando os diversos de episódios de condenação de postos de combustíveis por formação de cartel no Brasil (SDE, 2009), esta explicação ganha grande apelo. Nesse caso, a prescrição de política pública é óbvia: reforço no combate aos cartéis. Sendo assim, uma extensão natural deste artigo é a investigação das possíveis causas da assimetria, em especial se ela está relacionada com condutas coordenadas no varejo. Resultados preliminares indicam que o uso das informações da pesquisa de preços da Agência Nacional do Petróleo, Gás Natural e Biocombustíveis (ANP) é uma estratégia bastante promissora, pois permite isolar o efeito do poder de mercado no varejo pela construção de um painel de municípios, tal como em Deltas (2008).

No entanto, a literatura teórica tem apontado motivos para assimetria que independem da coordenação (tácita ou explícita) entre os varejistas [ver Tappata (2009) para referências]. Nesse caso, a prescrição de política pública é menos clara. Na verdade, sequer é óbvio se faz sentido algum tipo de intervenção do governo. Desse modo, restaria ao governo lidar com as consequências da assimetria. Duas delas chamam atenção.

A primeira se refere à condução da política monetária. Como choques positivos e negativos são transmitidos de forma diferente para os consumidores finais, a resposta da autoridade monetária deveria ser diferente em cada caso. Esta prescrição mostra-se mais relevante se a assimetria na transmissão de preços for regra e não exceção (Peltzman, 2000). Nesse sentido, uma possível extensão desse artigo é verificar se o mesmo fenômeno ocorre com relação ao índice de preços ao consumidor, que por conta do frete é afetado pelo preço do óleo diesel.

A segunda diz respeito à política de calibração da CIDE para minimizar a volatilidade dos preços dos combustíveis no varejo em resposta a choques no preço na refinaria (que acabam atingindo os preços nos distribuidores). Os resultados indicam que a redução da CIDE em resposta a incrementos de preços no atacado deveria ser imediata enquanto o aumento da CIDE em resposta à diminuição desses mesmos preços poderia ser gradual. 


\section{CONSIDERAÇÕES FINAIS}

Há uma farta literatura internacional indicando que há assimetria na transmissão de choques de custos para os preços no varejo, em particular no que se refere ao mercado de combustíveis. Nesse sentido, os resultados encontrados neste artigo confirmam esta evidência no caso brasileiro para diversos tipos de assimetria, tanto no curto prazo quanto no longo prazo. Por um lado, choques positivos nos preços do óleo diesel no atacado (refinaria e distribuidores) são repassados ao consumidor final pelos postos de combustível quase que integralmente no mesmo mês. Por outro lado, choques negativos apresentam repasse significativamente mais lento.

A título de ilustração, após quase um ano os impactos acumulados dos choques positivos e negativos ainda são significativamente distintos do ponto de vista estatístico. Para um choque de $1 \%$ no preço do óleo diesel no atacado, em comparação com o caso de repasse simétrico, essa discrepância implica na transferência de pelo menos R 2,1 bilhões por ano dos consumidores para os varejistas. Ressalte-se que, ao contrário de Von Cramon Taubadel e Meyer (2001), os resultados encontrados são robustos à presença de quebras estruturais na relação de longo prazo entre os preços do óleo diesel no varejo e no atacado.

Ademais, as evidências de assimetria na transmissão dos preços do óleo diesel têm implicações importantes em termos de política pública. Primeiro no que se refere à condução da política monetária: como choques positivos e negativos são transmitidos de forma diferente para os consumidores finais, a resposta da autoridade monetária deveria ser diferente em cada caso. Segundo no que diz respeito à política de calibração da CIDE para minimizar a volatilidade dos preços dos combustíveis no varejo em resposta a choques no preço do óleo diesel nas refinarias. A redução da CIDE em resposta a incrementos de preços no atacado deveria ser imediata enquanto o aumento da CIDE em resposta à diminuição desses mesmos preços poderia ser gradual. E finalmente no que tange à competição. Como uma das possíveis causas da assimetria está associada ao exercício de poder de mercado coordenado - explicação que ganha grande apelo considerando os diversos de episódios de condenação de postos de combustíveis por formação de cartel no Brasil (SDE, 2009) - os resultados encontrados podem sinalizar para a necessidade de se reforçar a política de combate aos cartéis nesse setor.

Por fim, embora tenha investigado um espectro bem amplo de assimetrias, este artigo não abordou assimetrias associadas a mudanças de regimes que são desencadeadas pelas próprias variáveis explicativas (Frey e Manera, 2007), usualmente investigadas com modelos de threshold [ver Chen et alii (2005), por exemplo]. Em particular, seria interessante verificar se, tal como sugerido em Meyer e Von Cramon Taubadel (2004), custos de ajuste preveniriam repasses para o consumidor final quando as variações de preço no atacado são muito pequenas.

\section{BIBLIOGRAFIA}

Alm, J., Sennoga, E., \& Skidmore, M. (2008). Perfect competition, urbanization, and tax incidence in the retail gasoline market. Economics Inquiry, 47:118-134.

Bachmeier, L. J. \& Griffin, J. M. (2003). New evidence on asymmetric gasoline price responses. Review of Economics and Statistics, 85:772-776.

Bai, J. \& Perron, P. (1998). Estimating and testing linear models with multiple structural changes. Econometrica, 66:47-78.

Boreinstein, S., Cameron, A. C., \& Gilbert, R. (1997). Do gasoline prices respond asymmetrically to crude oil price changes? Quarterly Journal of Economics, 22:429-451.

Carrion-I-Silvestre, J. L., Sansó-I-Rosselló, A., \& Ortuño, M. A. (2001). Unit root and stationarity tests' wedding. Economics Letters, 70:1-8. 
Chen, L.-H., Finney, M., \& Lai, K. S. (2005). A threshold cointegration analysis of asymmetric price transmission from crude oil to gasoline prices. Economics Letters, 89:233-239.

Cook, S. \& Vougas, D. (2007). Examining the robustness of cointegration analysis under weighted symmetric estimation. Applied Economics Letters, 14:711-714.

Cook, S. \& Vougas, D. (2008). A weighted symmetric cointegration test. Journal of Statistical Computation and Simulation, 78:559-565.

Davidson, R. \& Mackinnon, J. G. (1993). Estimation and Inference in Econometrics. Oxford University Press, New York, Oxford.

Deltas, G. (2008). Retail gasoline price dynamics and local market power. Journal of Industrial Economics, 56:613-628.

Engle, R. F. \& Granger, C. W. J. (1987). Co-integration and error correction: Representation, estimation, and testing. Econometrica, 55:251-276.

Frey, G. \& Manera, M. (2007). Econometric models of asymmetric price transmission. Journal of Economic Surveys, 21:349-415.

Greene, W. H. (2000). Econometric Analysis. Prentice Hall, Upper Saddle River.

Keblowski, P. \& Welfe, A. (2004). The ADF-KPSS test of the joint confirmation hypothesis of unit autoregressive root. Economics Letters, 85:257-263.

Lee, J. \& Strazicich, M. C. (2003). Minimum Lagrange multiplier unit root test with two structural breaks. Review of Economics and Statistics, 85:1082-1089.

Leybourne, S. J., Mills, T. C., \& Newbold, P. (1998). Spurious rejections by Dickey-Fuller tests in the presence of a break under the null. Journal of Econometrics, 87:191-203.

Madalla, G. S. \& Kim, I.-M. (1998). Unit Roots, Cointegration, and Structural Change. Cambridge University.

Meyer, J. \& Von Cramon Taubadel, S. (2004). Asymmetric price transmission: A survey. Journal of Agricultural Economics, 55:581-611.

Newey, W. K. \& West, K. D. (1987). A simple, positive semi-definite, heteroskedasticity and autocorrelation consistent covariance matrix. Econometrica, 55:703-708.

Peltzman, S. (2000). Prices rise faster than they fall. Journal of Political Economy, 108:466-502.

Perron, P. (1989). The great crash, the oil price shock and the unit root hypothesis. Econometrica, 57:1361-1401.

SDE (2009). Combate a cartéis na revenda de combustíveis. Brasília: SDE/MJ.

Tappata, M. (2009). Rockets and feathers: Understanding asymmetric pricing. RAND Journal of Economics, 40:673-687.

Uchôa, C. F. A. (2007). Testando a assimetria nos preços da gasolina brasileira. Revista Brasileira de Economia, 62:103-117.

Von Cramon Taubadel, S. \& Meyer, J. (2001). Asymmetric price transmission: Fact or artefact? Disponível em www. jochenmeyer.de/pdf/cramon-meyer.pdf. 


\section{A. APÊNDICE: TESTES DE QUEBRA ESTRUTURAL NO VETOR DE COINTEGRAÇÃO}

A Tabela A1 apresenta os resultados dos testes de quebra estrutural do vetor de cointegração (Bai e Perron, 1998). Nota-se que o modelo selecionado pelo critério de informação de Schwarz (marcado em negrito) é o de três quebras estruturais (em 08/2001, 07/2003 e 06/2008).

Tabela A1: Teste de Quebra Estrutural

\begin{tabular}{|c|c|c|c|c|c|c|}
\hline & 0 & 1 & 2 & 3 & 4 & 5 \\
\hline $\begin{array}{l}\text { Critério de informação de } \\
\text { Schwarz }\end{array}$ & $-582,869$ & $-710,892$ & $-740,433$ & $-763,056$ & $-755,165$ & $-740,716$ \\
\hline $\begin{array}{l}\text { Valor da função de máxima ve- } \\
\text { rossimilhança }\end{array}$ & 298,793 & 370,162 & 392,290 & 410,960 & 414,372 & 414,506 \\
\hline $\begin{array}{l}\text { Soma dos quadrados dos resí- } \\
\text { duos }\end{array}$ & 0,09450 & 0,03283 & 0,02365 & 0,01794 & 0,01705 & 0,01702 \\
\hline
\end{tabular}

No modelo selecionado (em negrito) as quebras foram estimadas em 08/2001, 07/2003 e 06/2008. 